\title{
Research on Employee Silence Behavior: A Review Based on Chinese Family Enterprise
}

\author{
Jie $\mathrm{Lu}^{1} \&$ Xiajuan $\mathrm{Xie}^{1}$ \\ ${ }^{1}$ School of Management, Jiangsu University, China \\ Correspondence: Jie Lu, School of Management, Jiangsu University, China. E-mail: lujie@mail.ujs.edu.cn
}

Received: July 28, 2013 Accepted: October 9, 2013 Online Published: November 29, 2013

doi:10.5539/ass.v9n17p47 URL: http://dx.doi.org/10.5539/ass.v9n17p47

\begin{abstract}
The employees in family business organization put forward ideas, suggestions and opinions based on their own experience and knowledge to improve performance and efficacy. Due to various reasons, they sometimes choose to hide their true thoughts or views. This kind of behavior is defined as employee silence. The article starts from a summary of the existing research on employee silence of family enterprises, such as definition, dimensions, antecedents and measurement methods, puts forward deficiencies, and provides measurements to improve sustainable development of human resource management.
\end{abstract}

Keywords: employee silence, family enterprise, antecedent variables, behavior

\section{Introduction}

In the modern enterprise, it is very common to see that staffs only give positive report to leaders of family business for fear of being blamed or do not dare to express their true opinions because of worrying about their different opinion would provoke the leader; some stuffs cannot express their views or thoughts in the discussion since fearing of being labeled negatively or just lacking of confidence in their recommendations could adopt by organizations; when facing with international issues, some staffs obviously have ideas to improve organizational performance but they just choose to keep silence because of their indifference to the interests and development of the organization, etc., This kind of situation describes common phenomenon: employee silence behavior. It is not only conducive to organizational bottom-up information exchange and communication, and reduced the quality of top leaders' decision, but also evoke the level of silent employees' work enthusiasm and satisfaction declining and affect development of their career. So, in recent years, the silence behavior of employees gets more and more attention from researchers both at home and abroad. The article comprehensively introduces the researches of employee silence behavior in family enterprises, discusses the possible disadvantages of current research and future research areas, and hope to attract domestic academia and business to draw attentions to the issue and strengthen the research and practice in this particular field.

\section{Definition and Dimensions of Employee Silence Behavior}

\subsection{The Definition of Employee Silence Behavior}

In the time of economic transition, Chinese family enterprise has faced the situation of lack of congenital resources controlling by the government and relationship orientation. The earliest research on employee silence behavior occurred in 1970s, Rosen \& Tesser's research shows that sometimes employees keep silent about their concerns. Individuals would limit the spread of bad news as far as possible or simply choose to remain silent because they do not want to become bad news communicators for negative message. The reason of this phenomenon is described as silent effect (also called mum effect). The official presentation of the academic concept of silence is in 2000; Morrison \& Milliken published a paper in journal of Management Review entitled Organizational silence: a barrier to change and development in a pluralistic world. According to the article, organizational silence is a collective-level phenomenon, which is the employee's choice to hold back their opinions and concerns about the organization. Pinder \& Harlos (2001) defined organizational silence as withholding genuine expression about behavioral, cognitive, and/or affective evaluations of organizational circumstances to people who seem capable of changing the situation, focusing more on individual employee silence as a response to injustice. Dyne et al. (2003) argued that before discussing the concept of employee silence we need to define the boundary conditions. Firstly, the silence behavior does not include unconscious 
behaviors. Secondly, we exclude silence behaviors that employees have no related ideas, information and opinions. Finally, we emphasize that employee silence occurs in face-to-face interaction between employees, such as meetings and discussions.

Based on China's cultural background and refereed to the views of previous researchers, A Chinese scholar Zheng Xiaotao (2008) defined employee silence behavior as: employees may raise suggestions, ideas and opinions based on their experience and knowledge so as to improve some works of the department or organization, due to various reasons they would choose to withhold opinions, or extract and filter their views. Ma Hui (2010) defined employee silence behavior based on " $4 \mathrm{w}$ " (who silence? Silence to whom? What is the problem of silence? What is the form?): employees (grassroots employees or managers) could have provided information, suggestions and ideas which can help to achieve organization goals to the organization inside and outside people, but because of various reasons they choose to withhold opinions and refine, filter or exaggerate their opinions.

\subsection{The Dimensions of Employee Silence}

After putting forward the concept of organizational silence, Pinder \& HarloS (2001) further divided it into two types: acquiescent silence and quiescent silence. Acquiescent silence refers to holding opinions negatively, which means passive obedience. The quiescent silence refers to holding opinions positively for the purpose of protecting the self, based on the fear that consequences of speaking up will be personally unpleasant. Building on the work of Pinder and Harlos, Dyne (2003) differentiated three types of silence based on employee motives: defensive silence, acquiescent silence and pro-social silence. The connotation of the defensive silence and acquiescent silence is the same as the quiescent silence and acquiescent silence which defined by Pinder \& Harlos (2001).But the difference is that Dyne (2003) put forward the pro-social silence based on organizational citizenship behavior, he defined it as withholding work-related ideas, information, or opinions with the goal of benefiting other people or the organization-based on altruism or cooperative motives. Similar to Defensive Silence, Pro-Social Silence is based on awareness and consideration of alternatives and the conscious decision to with-hold ideas, information, and opinions. In contrast to Defensive Silence, Pro-Social Silence is motivated by concern for others, rather than by fear of negative personal consequences that might occur from speaking up.

Owing to the influence of the culture, the structure of the employee silence may not be consistent in different countries; therefore, many Chinese scholars on the basis of west research achievements began to research on the employee silence with Chinese characteristics. Zheng Xiaotao (2008) investigated 928 domestic samples and adopted depth interview and semi-structured questionnaire, also draw lessons from foreign related research results, divided the employee silence into three dimensions: acquiescent silence, defensive silence and indifference silence, the first two dimensions are just similar to Pinder and Van Dyne's view, but the indifference silence rarely mentioned in western literatures, it refers to employees withholding ideas negatively for their low levels of commitment and immixture to the organization, that means disregard the interests of the organization. Zhang Min (2009) differentiated three types of silence based on the different macro factors leaded to the behavior: institutional silence, cultural silence and structural silence. Zhao Chunlian (2010), based on summary of existing research on influencing factors of staff silence behavior: leadership, organization, colleagues, and individual employees, divided employee silence of Chinese enterprise into three corresponding dimensions: organization system barrier of silence, interpersonal fear silence and low self-esteem individuals silence. Ma Hui (2010) combined " $4 \mathrm{w}$ " theory with the phenomenon of silence according to the behavior change theory, divided it into double-win silence, no-win silence, silence behavior which damage to individual and benefit the whole organization, and damage to the whole organization and benefit individual, etc.

\section{Influencing Factors of Employee Silence Behavior}

The reasons that staffs choose to be silent is various, scholars at home and abroad have studied from several aspects and achieved some results. Throughout research achievements of predecessors, what kind of elements would affect employee to be silent can be summarized as individual factor, colleague factor, organizational leadership factor and culture factor.

\subsection{Individual Factors}

Until now, considering individual factors associated with silence behavior, research mainly focused on gender, internal psychological perception, personality characteristics, self-monitoring and self-esteem level, etc.

Gilligan (1982) believed that women's behavior tends to show more relationship orientation, accordingly, when women express their opinions they often need to consider other people's social relations and social acceptance and, therefore, compared to men, women show more silence behavior. Ryan \& Oestrdch's study shows that the 
individual factor is the main reason of employee silence. When individuals perceive that expressing opinions would lead to a bad result or would not produce an expected role and influence, they will choose to remain silence. Milliken (2003) developed a structure model of employee silence factors by the means of interview. He considered that the key variable is employees' individual psychological perception which mainly includes six kinds of fear: being negatively labeled or viewed, damaged relationships, belief that speaking up will not make a difference, retaliation or punishment and negative impact on others. Bowen \& Blaekmon (2003) considered that when people feels that his supported views tend to predominate or get the upper hand, he will be more likely to speak up, otherwise be silent. Empirical study of Lepine \& VanDyne (1998)shows that the outgoing staff who have strong sense of responsibility tend to express their opinions, the easy-going employee tend to remain silent for unwilling to make troubles and destroy the interpersonal relationships . Empirical study of Duan Jinyun etc. (2007) shows that accountability, extroversion has a positive correlation with voice behavior, neuroticism, openness are negatively related to voice behavior.

Lepine \& VanDyne, Jeffrey, Premeaux believed that employees self-esteem level will affect their advice behavior, the low levels are more inclined to protect themselves and do not want to expose themself to be attacked by others, so they are more likely to choose silence. In an integrated model of Premeaux \& Bedeian (2003), it is to be proved that the individual self-esteem, self-monitoring, and control of internal and external source would affect the expression behavior in the organization. The externals are more negative and passive, while the internals have stronger sense of controlling works and therefore are more likely to speak up; individuals with low levels of self-esteem are oriented toward self-protection and, thus, are unlikely to put themselves in positions of vulnerability, and consequently, tend to be silence; the self-monitoring is regulated variable of the model for the reason that individuals with high level of self-monitoring are better at managing their image in public.

\subsection{Leadership and Organizational Factors}

Morrison \& Milliken (2000) argued that organizational silence is primarily caused by managers; the root cause is manager's worries of negative feedback and their series of within ideas. Morrison classified managers' inner ideas to three categories: employees are selfish and not to be trustworthy, managers mostly understand the important issues in the organization and harmony is the embodiment of the organizational health. Korsgaard, Roberson and Rymph (1998) considered that when the negative feedback is from subordinates, it often be considered as irrational and be threat to the power of the managers. Just because of the managers' inner ideas and the fear for the employees' negative feedback information, the organization adopted centralized decision-making and lack of upward feedback mechanism and then an atmosphere of silence would formed in the organization. Edumondson's (2003) study emphasized the important role of leadership in eliminating organizational silence, if leaders can prompt employees to produce psychological security, it may be conducive to eliminate organizational silence.

Huang (2003) found that the openness of leaders is inversely proportional to the frequency of the organizational silence, the organization is more open, and the employees are more likely to expression their opinions for the issues. Zheng Xiaotao's (2008) empirical research also suggests that employee's trust in the superior has significant negative influence on employee silence. In addition, the relationship between superior and subordinate is also an important factor to affect employee silence. Li Rui, LingWen Quan's (2010) empirical research suggests that perceived supervisor support would significantly improve employees' attitude for job and the organization, and would increase their enthusiasm for breaking silence and speaking up.

In addition, Chinese scholars began to explore the influence mechanism of the paternalistic leadership which rooted in Chinese society to affect employee silence behavior. Tang Hongrui (2012) discussed in private enterprises the relationship between the style of Paternalistic leadership and employee silence and the regulating role that superior-inferior relationship plays in, the empirical shows that the Authoritarian leadership of the Paternalistic leadership has a significant positive correlation to employee silence behavior. Sun Fei (2012) proved that the Authority leadership has a significant positive effect on employee silence, and the power distance and the golden mean separately plays the role of negative and positive regulation in the relationship in his master thesis.

Morrison and Mi11iken (2000) developed a factors model of employ silence behavior, which includes factors of environmental and organizational characteristics which covers the organization atmosphere, the rules and regulations, organizational structure and organizational culture etc., and these factors will lead to employee silence behavior. Frances Bowen \& Kate Blackmon's study shows that whether employees put forward proposals is closely associated with organizational climate (such as unity, trust). The united and trusting climate makes for information exchange and communication between employees and superiors and among employees. 
On the contrary, if the organization creates a fear atmosphere, it can make employees afraid to remonstrate and remain silent. Pinder and HarloS' (2001) research shows that unfair environment in the organization can lead to employee silence. The empirical study of Liu Pengpeng (2011) shows that the employee silence behavior influenced by distributive justice and procedural justice, and the procedural justice is the primary factor, exerting a bigger impact on employee silence, while the interpersonal justice and information justice have no significant effect on it.

\subsection{Colleague Factors}

Existing research shows that employees' words and deeds are influenced by the pressure of the collective and employee silence is a collective phenomenon. Ashforth \& HumPhrey (1995) emphasized the influence of the "label" in organization. When a staff is labeled, other staffs will measured him by the label. Commented regularly is likely to be negatively labeled, the worst situation would affect employees' promotion opportunities and career development. Bowen \& Blackmon (2003) argued that when employees decide whether to give comments, they largely affected by the perceived colleague's point of view. When they feel their personal viewpoint is one of few people's, for fear of being isolated they would not confess fully of their ideas. Moorhead \& Monranari (1986) believed that employees are more likely to express their views in the case of good relationship between employees and colleagues and high group cohesiveness.

\subsection{Cultural Factors}

Cultural factors is an important antecedent of employee silence behavior, different cultural factor will cause different type of silence behavior. Hofstede's study of national culture found that Chinese national culture shows a high power distance, collectivism and long-term tendency. Clugston, Howell and Dorfman's research (2000) shows that when leaders show the authoritarian style, high power distance oriented individuals are more likely to conform to authority and listen to the leader's instructions and then show higher silence behavior. Huang (2003) suggested that the culture of power distance is positively related to employee behavior of withdrawing views. Many Chinese scholars put forward that the Chinese traditional culture such as Confucian culture, relatively high power distance, Collectivism concept, such as mianzi and guanxi, are the cultural roots of employee silence behavior under the background of China. The researchers believed that the golden mean that the Confucian culture pursued and the harmony philosophy drive employees keep silence in order to maintain organizational or interpersonal harmony when they find out problems or have any other objection. To be worldly-wise and play safe of the Confucian culture, "The squeaky wheel gets the grease", "Names are debts", these old adages also drive employees keep silence for fear of retribution and punishment or worrying about lose their trust and respect when they want to express their dissent. The cultural consciousness of mianzi and guanxi are deeply rooted in the Chinese society, Chinese family businesses would rather put up with or obey relevant opinions and show the acquiescent silence in order to protect themselves or save other's face and avoid the risk of image.

\section{Effect of Employees' Silence Behavior in Family Enterprises}

\subsection{The Active Effect of Employee Silence Behavior}

Research stated that employee silence behavior have some active influences on person and organization in special organization environment, such as in family enterprises. Dyne (2003) considered that the pro-social silence which based on the motivation of altruism and cooperation is a kind of active silence behavior, and it is same like sportsmanship in the behavior of organizers. They don't care themselves' getting and lost, but breathing and suffering together with organization and also protecting organization's benefit. Liang Yin (2009) pointed out that some silence is good for organization management, improvement of decision quality and policy executive ability, promoting personal observation and thinking fully.

\subsection{The Negative Effect of Employee Silence Behavior}

\subsubsection{The Effect on Family Enterprises}

Morison and Milliken (2000) think the silence restrict decision-makers to secure useful information and also restrict critical analysis of the view and then will bring down the effectiveness of decision-making. At the same time, if employees kept silence, they will not feedback any information, so, family enterprises cannot observe issues and take corrective actions immediately. It will make organization reforming in vain and decline organization performance. Van Dyne \& Le Pine (1998), Edmondson (2003) think that employee silence will impede family businesses' innovation, because this special kind of family business more need employees to point out new ideas and new thoughts, also query in innovation process. Organization will lost many new innovation chances if employee did not feedback points and information to the organization. Dundone's test also stated that voice in organization is good for achieving organization benefit. 


\subsubsection{The Effect on Personnel}

Morrison and Milliken's (2000) research shows that silence have three types influence on employee: a feel of nebbish, lack of controlling and cognitive dissonance. When employees have those feelings, it will affect employee's working satisfaction, commission, work activeness and work press, even lead to asking leave. Research of Qian Xiaojun and Zhan Xiaoli (2005) stated that good communicating atmosphere in organization can increase employees' satisfaction. Zheng Xiaotao (2007) though that employee silence will make employee query the importance of them, decrease the satisfaction to the environment, have a kind of anxiety to body and heart. Jia Juannong (2009) pointed out that long-time silence will make employee have an emotion of "mental strike", if so, employee will become "invisible employee" in company.

\section{The Measurement and Forecast of Employee Silence Behavior}

The feature of silence is no language and the supplied action clue is obscure, so the measurement of employee silence behavior will be a challenge in this research field. Now the main measure types are: self-assessment, peer assessment and observation on-site.

Dyne (2003) used peer assessment based on the concept of employee silence to assess colleague's behavior from three aspects: acquiescent silence, defensive silence and pro-social silence, each aspect includes five items and adopted Likert scale, in 7 point scale, number 1 means very dissatisfied, number 7 means very satisfactied. Huang (2003) applied self-assessment to ask employee to assess organization's 27 items from 5 aspects such as communication ways, and at last they used average marks to show the silence degree of organization. Edmondson (2003) adopted observation on site to assess 16 medical team, they set up a working condition, and keep reaction on file and code to get the result of silence. Milliken (2003) applied semi-structure interviewing method to work out employee's silence action. Zheng Xiaotao took Chinese employees as research object to develop employee silence behavior scale by ways of interview and open questionnaire survey. So, there is no very mature measure of silence in academic world. Many researchers are researching and discussing the measure ways of employee silence.

Now there are some empirical researches about dependent variable before employee silence. Researchers have studied the relationship between employee silence and organization support perception, organization trust, leadership trust, organization justice, leadership style and psychological possession. Vakola and Bouradas (2005) studied organizational commitment and job satisfaction as a result of employee silence behavior variables. But the study of outcome variable of employee silence is scarcely.

From all above, the article points out that cross-cultural research needs to be strengthened. From the point of current literature, most studies of employee silence are mainly completed in western countries especially the United States; studies under the background of Chinese culture are very rarely. The values of Chinese culture such as Confucianism, collectivism, high power distance, mianzi and renqing, which are different from western society, these all will have influence on employee's silence behavior. Future research would more focus on the background of Chinese culture, develop an integrated model and influence factors and outcome variables of Chinese employees science behavior.

\section{References}

Ashforth, B. E., \& Humphrey, R. H. (1995). Labeling processes in the organization: constructing the individual. In L. L. Cummings, \& B. W. Staw (Eds.), Research in Organizational Behavior, Greenwich, CT: JAI Press, 5 (pp. 413-461).

Bowen, F., \& Blackmon, K. (2003). Spirals of Silence: The Dynamic Effects of Diversity on Organizational Voice. Journal of Management Studies, 40(6), 1393-1417. http://dx.doi.org/10.1111/1467-6486.00385

Clugston, M., Howell, J. P., \& Dorfman, P. W. (2000). Does cultural socialization predict multiple bases and foci of commitment? Journal of Management, 26, 5-30.

Duan, J. Y., Wang, C. M., \& Zhong, J. A. (2007). A Research on the Impact of Big Five and Perceived Organizational Justice on Voice Behavior. Journal Psychological Science, 30(1), 19-22.

Dundon, T., Wilkinson, A., Marchington, M., \& Ackers, P. (2004). The Meanings and Purpose of Employee Voice. International Journal of Human Resource Management, 15(6), 1149-1170. http://dx.doi.org/10.1080/095851904100016773359

Dyne, L. V., Ang, S., \& Botero, I. C. (2003). Conceptualizing Employee Silence and Employee Voice as Multidimensional Constructs. Journal of Managerial Studies, 9, 1359-1392. http://dx.doi.org/10.1111/1467-6486.00384 
Huang, X., Vliert, E. V., \& Vegt, G. V. (2003). Break the silence: do management openness and employee involvement raise employee voice worldwide. Academy of Management Proceedings, 2, 126.

Lepine, J. A., \& Dyne, L. V. (2001). Voice and Cooperative Behavior as Contrasting Forms of Contextual Performance: Evidence of Differential Relationships with Big Five Personality Characteristics and

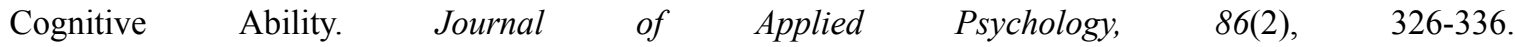
http://dx.doi.org/10.1037/0021-9010.86.2.326

Ma, H. (2010). The Analysis of Employee Silence Based on Behavior Shift. Journal of Applied Psychology, (5), 320-323.

Milliken, F. J., Morrison, E. W., \& Hewlin, P. F. (2003). An exploratory study of employee silence; issues that employees don't communicate upward and why. Journal of Management Studies, 40(6), 1453-1476. http://dx.doi.org/10.1111/1467-6486.00387

Morrison, E., \& Milliken, F. J. (2000). Organizational silence: a barrier to change and development in a pluralistic world. Academy of Management Review, 25, 706-725.

Rosen, S., \& Tesser, A. (1970). On Reluctance to Communicate Undesirable Information: the Mumeffect. Society, $33,63-253$.

Yan, X. H. (2012). The Influence and Mechanisms of Leader-Member Exchange to Voice Behavior. Zhejiang industry and commerce university.

Yao, S. J., Deng, Y. N., \& Zheng, J. H. (2009). The Cultural Roots of Employee Silence under the Background of China. East China Economic Management, (6), 135-138.

Zhang, M. (2010). A little thinking about employee silence behavior classification. Management Space, 9, 32-33.

Zhao, C. L. (2012). Study on Status of Organizational Silence and Countermeasures under the Chinese Background. Chong Qing University.

\section{Copyrights}

Copyright for this article is retained by the author(s), with first publication rights granted to the journal.

This is an open-access article distributed under the terms and conditions of the Creative Commons Attribution license (http://creativecommons.org/licenses/by/3.0/). 